\title{
Diabetic retinopathy in Down's syndrome
}

Tim Fulcher, Margaret Griffin, Seamus Crowley, Richard Firth, Robert Acheson, Niall O'Meara

\begin{abstract}
Aim-To determine the prevalence of diabetic retinopathy in patients with Down's syndrome and diabetes mellitus.

Method-Nine patients with Down's syndrome and diabetes mellitus were assessed. Factors recorded included type and duration of diabetes, level of diabetic control, blood pressure, urinalysis, and results of ophthalmological examination. Results-The duration of diabetes ranged from 8 to 41 years (mean 17.6 years). All had satisfactory glycaemic control and blood pressure measurements on the low side of normal (mean $106.6 / 70 \mathrm{~mm} \mathrm{Hg}$ ). One patient had early background diabetic retinopathy. The remainder had no evidence of diabetic retinopathy.

Conclusion-The low prevalence of diabetic retinopathy in these Down's syndrome patients, despite the long duration, is an interesting finding. It suggests some inherent protective factor against the development of diabetic retinopathy in this patient subgroup.

(Br f Ophthalmol 1998;82:407-409)
\end{abstract}

Diabetes is an important cause of blindness in developed countries. The precise cause of diabetic retinopathy in patients with diabetes mellitus has not been defined. Definite contributing factors include chronic hyperglycaemia ${ }^{1-4}$ and the duration of diabetes. ${ }^{5}$ The presence of coexisting hypertension ${ }^{67}$ and hormonal changes associated with puberty and pregnancy may also contribute. By contrast, certain factors may be protective including glaucoma, ${ }^{8}$ myopia, ${ }^{9} 10$ and ipsilateral carotid artery disease. ${ }^{11}$

Down's syndrome (trisomy 21) is a chromoOphthalmology, Mater Misericordiae Hospital, Dublin, Ireland

T Fulcher

$\mathrm{R}$ Acheson

Department of Endocrinology, Mater Misericordiae Hospital, Dublin, Ireland

M Griffin

S Crowley

N O'Meara

R Firth

Correspondence to: $\mathrm{Mr} \mathrm{T}$ Fulcher, Institute of Ophthalmology, 60 Eccles Street, Dublin 7, Ireland.

Accepted for publication 28 October 1997 \section{in the Mater Misericordiae Hospital were included in this study. The diabetic unit has been established for over 30 years. There are \\ Patients and methods \\ All patients with Down's syndrome and diabetes mellitus who attend the diabetic unit}

currently 6000 active attenders. All patient data are recorded on a computerised database, which is updated annually. In Ireland, diabetes care is hospital based. Thus, this group is probably representative of the population of diabetics at large. Information about all patients with Down's syndrome and diabetes mellitus was retrieved from the database, and patients were invited to attend for an ophthalmological assessment. The group in this study represents the entire population of patients with Down's syndrome and diabetes from our unit.

The ophthalmological examination included orthoptic assessment, refraction, slit lamp examination, funduscopy with a direct ophthalmoscope, 90 dioptre lens, and fundus photographs for cooperative patients.

Other factors recorded included: type of diabetes, duration of diabetes, mean glycosylated haemoglobin $\left(\mathrm{HbA}_{1 \mathrm{c}}\right)$ over the previous 5 years, most recent blood pressure measurement, and the presence of proteinuria (measured by dipstick analysis and 24 hour urinary collection when positive).

\section{Results}

There were nine patients included in the study, eight females and one male. The ages ranged from 25 to 44 years (mean 37.2 years). Seven had insulin dependent diabetes mellitus (IDDM) and two had non-insulin dependent diabetes mellitus (NIDDM). The duration of diabetes in the group with IDDM ranged from 8 to 41 years (mean 20 years). In the two patients with NIDDM the duration was 9 and 10 years respectively.

The ophthalmic clinical features are summarised in Table 1. Four patients had esotropia, four had blue dot lens opacities, and one had keratoconus. Refraction showed that four patients were myopic (ranging from -6 to -9 dioptres), two were emmetropic, and three had compound hypermetropic astigmatism. On funduscopic examination, no evidence of diabetic retinopathy was present in six out of seven $(85.7 \%)$ patients with IDDM. The remaining patient had minimal background diabetic retinopathy, with only a few microaneurysms being present. Neither patient with NIDDM had any diabetic retinopathy.

The patient characteristics are summarised in Table 2. Blood glucose control was assessed by the mean glycosylated haemoglobin $\left(\mathrm{HbA}_{1 \mathrm{c}}\right)$ during the previous 5 years. Mean $\mathrm{HbA}_{1 \mathrm{c}}$ levels ranged from $6.4 \%$ to $9.1 \%$ (normal range $4.2 \%$ to $6.2 \%$ ).

Systolic blood pressure measurements ranged from 90 to $130 \mathrm{~mm} \mathrm{Hg}$ (mean $106.6 \mathrm{~mm} \mathrm{Hg}$ ). Diastolic blood pressure measurements ranged 
Table 1 Ocular features of patients in this study

\begin{tabular}{llllll}
\hline Patient no & Retinopathy & Cataract & Keratoconus & Strabismus & Refraction \\
\hline 1 & Absent & Yes & No & Yes & Hyperopic astigmatism \\
2 & Present & No & No & No & Emmetropic \\
3 & Absent & No & No & Yes & Hyperopic astigmatism \\
4 & Absent & Yes & No & No & Myopic \\
5 & Absent & No & No & Yes & Myopic \\
6 & Absent & No & No & Yes & Hyperopic astigmatism \\
7 & Absent & Yes & No & No & Emmetropic \\
8 & Absent & No & No & No & Myopic \\
9 & Absent & Yes & Yes & No & Myopic \\
\hline
\end{tabular}

Table 2 Systemic features of patients in study

\begin{tabular}{|c|c|c|c|c|c|c|}
\hline Patient no & $\begin{array}{l}\text { Type of } \\
D M\end{array}$ & $\begin{array}{l}\text { Duration of } \\
\text { DM }\end{array}$ & $\begin{array}{l}\text { Blood } \\
\text { pressure }\end{array}$ & Mean $\mathrm{Hb} A_{1 c}$ & Urinary protein & Retinopathy \\
\hline 1 & IDDM & 24 years & $110 / 70$ & $9.1 \%$ & Negative & Absent \\
\hline 2 & IDDM & 8 years & $100 / 70$ & $8.2 \%$ & Positive & Present \\
\hline 3 & IDDM & 13 years & $110 / 70$ & $7.5 \%$ & Negative & Absent \\
\hline 4 & IDDM & 41 years & $130 / 80$ & $7.9 \%$ & Negative & Absent \\
\hline 5 & IDDM & 24 years & $110 / 70$ & $7.9 \%$ & Positive & Absent \\
\hline 6 & IDDM & 18 years & $90 / 60$ & $8.5 \%$ & Negative & Absent \\
\hline 7 & IDDM & 12 years & $110 / 70$ & $6.6 \%$ & Negative & Absent \\
\hline 8 & NIDDM & 9 years & $110 / 70$ & $6.4 \%$ & Negative & Absent \\
\hline 9 & NIDDM & 10 years & $90 / 70$ & $7.4 \%$ & Negative & Absent \\
\hline
\end{tabular}

$\overline{\mathrm{DM}}=$ diabetes mellitus; $\mathrm{IDDM}=$ insulin dependent diabetes mellitus; $\mathrm{NIDDM}=$ non-insulin dependent diabetes mellitus.

from 60 to $80 \mathrm{~mm} \mathrm{Hg}$ (mean $70 \mathrm{~mm} \mathrm{Hg}$ ). Mean arterial pressures ranged from 70 to 97 $\mathrm{mm} \mathrm{Hg}$ (mean $82 \mathrm{~mm} \mathrm{Hg}$ ).

Urinalysis was negative for protein on all occasions in seven of nine patients $(77.7 \%)$. The remaining two patients had positive dipstick analysis and subsequently had 24 hour urinary collections for protein. One had non-significant proteinuria (0.22 g/24 hours), the other had significant proteinuria $(0.48 \mathrm{~g} / 24$ hours). Interestingly this latter subject was the single patient who had mild background diabetic retinopathy.

\section{Discussion}

The prevalence of diabetic retinopathy was reported in the Wisconsin Epidemiologic Study of Diabetic Retinopathy as $97 \%$ in those who had diabetes for 15 or more years, when the age at diagnosis of diabetes was less than 30 years. ${ }^{5}$ In our current study, diabetes mellitus was diagnosed in eight patients with Down's syndrome before the age of 30 years and at 34 years in the remaining patient. The mean duration of diabetes in those diagnosed before the age of 30 years was 18.75 years. Only one patient had any signs of diabetic retinopathy. This suggests a protective factor against the development of retinopathy in Down's syndrome patients.

Chronic hyperglycaemia is an important risk factor in the development of diabetic retinopathy. The Diabetes Control and Complications Trial (DCCT) proved conclusively that tight blood glucose control reduced the risk of developing retinopathy by $76 \%$ over a 6.5 year period. ${ }^{4}$ In that study the mean glycosylated haemoglobin $\left(\mathrm{A}_{1 \mathrm{c}}\right)$ in the intensively treated group was $7.2 \%$. In our study, the mean $\mathrm{HbA}_{10}$ was $7.72 \%$ (SD $0.86 \%$ ). This is between the intensively and conventionally treated range of the DCCT and indicates satisfactory control. However, after 9 years the percentage of patients who developed retinopathy was about $15 \%$ in the intensively treated group, and about $55 \%$ in the conventionally treated group. In our study, only one patient out of nine developed any signs of diabetic retinopathy despite a mean duration of 17.6 years.

Hypertension has been associated with an increased incidence of severe diabetic retinopathy. ${ }^{6}{ }^{12-15}$ In patients with IDDM this is reported to be associated with an elevated diastolic blood pressure above the 75th percentile. ${ }^{16}$ In the same study it was shown that an increased incidence of retinopathy also occurred in patients with high/normal blood pressure. Other studies have shown a significant association between systolic blood pressure (above $140 \mathrm{~mm} \mathrm{Hg}$ ) and an increased prevalence of retinopathy. ${ }^{17-19}$ This effect of increasing blood pressure on the subsequent development of diabetic retinopathy, may be mediated through the accompanying increase in retinal blood flow in a setting where the normal autoregulatory responses to changes in blood pressure are impaired..$^{19}{ }^{20}$ In the patients with Down's syndrome in this study, all blood pressure measurements were on the low side of normal. Mean systolic pressure was $106.6 \mathrm{~mm}$ $\mathrm{Hg}$ and mean diastolic pressure was $70 \mathrm{~mm}$ $\mathrm{Hg}$. This may be significant in protecting this group from developing diabetic retinopathy. The absence of hypertension may also reflect the absence of clinical nephropathy in our patient group.

Myopia has been shown to be protective against diabetic retinopathy. ${ }^{9}{ }^{10}$ The study by Rand et al ${ }^{10}$ showed that patients with HLA-D group antigen markers of IDDM and no significant refractive error had 3.74 times the risk of developing proliferative retinopathy when compared with patients with HLA-D group antigen markers of IDDM and myopia of 2 dioptres or more. Four patients in our study had myopia ranging from -6.0 dioptres to -9.0 dioptres. None had diabetic retinopathy.

Short stature is a characteristic feature of Down's syndrome. Affected children have severe postnatal growth arrest which can be partially reversed by growth hormone therapy. ${ }^{21}$ Furthermore, growth hormone deficiencies have been described in some but not all series of cases of Down's syndrome. ${ }^{22} 23$ There are extensive data in the literature implicating growth hormone in the pathogenesis of diabetic retinopathy ${ }^{24}$ and the absence of diabetic retinopathy has previously been reported in a group of sexual ateliotic dwarfs with poorly controlled diabetes. ${ }^{25}$ It is possible that abnormalities in growth hormone secretion or responsiveness in Down's syndrome could account for the low prevalence of diabetic retinopathy noted in this study.

In conclusion, the development of diabetic retinopathy, while driven by hyperglycaemia, may be modulated by a number of other factors. The low prevalence of retinopathy in Down's syndrome patients with diabetes suggests such factors may be operational here. Their relatively low blood pressures may be an important protective factor. Other unidentified factors may also play a role, including the possibility of growth hormone deficiencies in 
Down's syndrome patients. The observations in this study may further aid our understanding of the pathogenesis of diabetic retinopathy in affected individuals. The results should also be confirmed in a multicentre clinical study.

The authors would like to thank Dr Mary Codd for her advice during the preparation of this manuscript.

1 Dahl-Jorgenson $\mathrm{K}$, Brinchman-Hanson O, Hanssen KF, Sandvik L, and the Aker Diabetes Group. Rapid tightening of blood glucose control leads to transient deterioration of retinopathy in insulin-dependent diabetes mellitus. The Oslo study. BMF 1985;290:811-5.

2 Kroc Collaborative Study Group. Blood glucose control and the evolution of diabetic retinopathy and albuminuria. $N$ Engl F Med 1984;311:365-72.

3 Lauritzen T, Larsen HW, Frost-Larsen K, Deckert T, and The Steno Study Group. Effect of 1 year of near-normal The Steno Study Group. Effect of 1 year of near-normal
blood glucose levels on retinopathy in insulin dependent blood glucose levels on retin
diabetics. Lancet 1983;i:200-4.

4 DCCT Research Group. The effect of intensive treatment of diabetes on the development and progression of long-term complications in insulin dependent diabetes mellitus. N Engl F Med 1993;329:977-86.

5 Klein R, Klein BEK, Moss SE, Davis MD, DeMets DL. The Wisconsin Epidemiologic Study of Diabetic Retinopathy. 2 Prevalence and risk of diabetic retinopathy when age at diagnosis is less than 30 years. Arch Ophthalmol 1984;102: $520-6$.

6 Knowler WC, Bennett PH, Ballintine EJ. Increased incidence of retinopathy in diabetics with elevated blood pressure: a six-year follow-up study in Pima Indians. N Engl pred 1980;302:645-50.

7 Kornerup T. Studies in diabetic retinopathy: an investigation of 1,000 cases of diabetes. Acta Med Scand 1955;153. tion of 1 .

8 Becker B. Diabetes and glaucoma. In: Kimura SJ, Caygill, WM, eds. Vascular complications of diabetes mellitus. St Louis: WM, eds. Vascular complications

9 Jain IS, Luthra CL, Das T. Diabetic retinopathy and its relation to errors of refraction. Arch Ophthalmol 1967;77:5960.

10 Rand LI, Krolewski AS, Aiello LM, et al. Multiple factors in the prediction of risk of proliferative diabetic retinopathy. $N$ Engl F Med 1985;313:1433-8.
11 Gay AJ, Rosenbaum AL. Retinal artery pressure in asymmetric diabetic retinopathy. Arch Ophthalmol 1966;75: asymme

12 Blankenship GW, Skyler JS. Diabetic retinopathy: a general survey. Diabetes Care 1978;1:127-37.

13 Szabo AJ, Stewart AG, Joron GE. Factors associated with increased prevalence of diabetic retinopathy. Can Med Assoc 7 1967;97:286-92.

14 Klein R, Klein BEK, Moss SE, Davis MD, DeMets DL. The Wisconsin Epidemiologic Study of Diabetic Retinopathy. IX Four year incidence and progression of retinopathy
when the age at diagnosis is less than 30 years. Arch when the age at diagnosis is
Ophthalmol 1989;107:237-43.

15 Klein R, Klein BEK, Moss SE, DeMets DL. Blood pressure and hypertension in diabetes. Am F Epidemiol 1985;122:7589 .

16 Chase HP, Garg SK, Jackson WE, et al. Blood pressure and retinopathy in type 1 diabetes. Ophthalmology 1990;97: 155-9.

17 Lewis JM, Jovanovic-Peterson L, Ahmadizadeh I, et al. The Santa Barbara County diabetic retinopathy screening feasibility study: significance of diabetes duration and systolic blood pressure. F Diabetes Complications 1994;8:51-4.

18 Cignareeli M, DeCicco ML, Damato A, et al. High systolic blood pressure increases prevalence and severity in NIDDM patients. Diabetes Care 1992;15:1002-8.

19 Kohner EM, Patel V, Rassam SMB. Role of blood flow and impaired autoregulation in the pathogenesis of diabetic retinopathy. Diabetes 1995;44:603-7.

20 Patel V, Rassam S, Newsom R, Wiek J, Kohner E. Retinal blood flow in diabetic retinopathy. BMF 1992;305:678-83.

21 Anneren G, Gustafsson J, Sara VR, Tuvemo T. Normalised growth velocity in children with Down's syndrome during growth hormone therapy. F Intellect Disabil Res 1993;37: $381-7$.

22 Barreca A, Rasore-Quartino A, Actis MS, et al. Assessment of growth hormone insulin like growth factor-1 axis in Down's syndrome. F Endocrinol Invest 1994;17:431-6.

23 Castells S, Torrado C, Bastian W, Wisniewski KE. Growth hormone deficiency in Down's syndrome children. F Intellect Disabil Res 1992;36:29-43.

24 Alzaid AA, Dinneen SF, Melton LJ, Rizza RA. The role of growth hormone in the development of diabetic retingrowth hormone in the development

25 Merimee TJ. Comparative metabolic and clinical studies of sexual ateliotic dwarfs and diabetics in Camerini. Vascular and neurological changes in early diabetes. New York: Academic Press, 1978:207-13. 